\title{
INFRAESTRUCTURAS PARA LA PAZ Y JUSTICIA TRANSICIONAL EN COLOMBIA
}

\section{INFRASTRUCTURES FOR PEACE AND TRANSITIONAL JUSTICE IN COLOMBIA}

\author{
Tania Galaviz Armenta*
}

\author{
Fecha de recepción: 6 de febrero de 2018 - Fecha de aceptación: 4 de julio de 2018
}

\begin{abstract}
Resumen
El artículo analiza la interacción entre la Justicia Transicional y las Infraestructuras para la Paz. Para ello, se presentan algunas de las características del conflicto armado y los procesos de negociación con las Fuerzas Armadas Revolucionarias de Colombia durante el periodo 1982-2016, así como los antecedentes de la Justicia Transicional en dicho país. Además, se examinan las Infraestructuras para la paz, entendidas como mecanismos que generan dinámicas de interdependencia entre distintos grupos sociales para la construcción de paz. Derivado de un análisis documental se concluye que, en el caso colombiano, la Justicia Transicional interactúa con las Infraestructuras para la Paz al vincular el cumplimiento de las sanciones restaurativas con las acciones para el desarrollo territorial comunitario realizadas desde los Comités Locales de Paz.
\end{abstract}

Palabras clave: Construcción de paz, Víctimas, Participación social, Conflicto armado, FARC

\begin{abstract}
The article analyzes Colombia's interaction between its Transitional Justice and its Infrastructures for Peace. For this purpose, the article presents some of the characteristics of the armed conflict and negotiation processes associated to the Revolutionary Armed Forces of Colombia during the period 1982-2016 along with the country's Transitional Justice background. In addition, itexamines the Infrastructures for Peace, understood as mechanisms that generate interdependence dynamics between different social groups for peacebuilding. From a documentary analysis, it is concluded that Colombian Transitional Justice interacts with its Infrastructures for Peace by connecting the compliance of restorative sanctions to the actions for the community territorial development carried out by Local Peace Committees.
\end{abstract}

Key Words: Peacebuilding, Victims, Social participation, armed conflict, FARC

Universidad Autónoma del Estado de Morelos, México, Centro de Investigación en Ciencias Sociales y Estudios Regionales, tgalaviz@uaem.mx 


\section{Introducción}

El 12 de noviembre del 2016, el Gobierno de Juan Manuel Santos (2010-2014 y 2014-2018) y las Fuerzas Armadas Revolucionarias de Colombia (FARC) firmaron el Acuerdo Final para la Terminación del Conflicto y la Construcción de Paz Estable y Duradera. Con él se puso fin a más de 50 años de conflicto armado en el país. Dicho acuerdo no sólo fue producto de una negociación entre las partes en conflicto, sino también, con las personas opositoras al proceso de paz. Una parte central de este acuerdo, fue la creación del Sistema Integral de Verdad, Justicia, Reparación y No Repetición, que a nivel de Latinoamérica es uno de los mecanismos de Justicia Transicional más completos.

El presente trabajo analiza la interacción entre la Justicia Transicional y las Infraestructuras para la Paz, propuesta de John Paul Lederach (1997). Para ello, se toma como caso de análisis el Acuerdo Final firmado por el gobierno colombiano y las FARC en noviembre de 2016. Con este objetivo, el artículo se encuentra dividido en cuatro apartados. En el primero de ellos se realiza un sucinto análisis del conflicto armado colombiano, el surgimiento de las FARC y las negociaciones con las seis presidencias comprendidas en el periodo 1982-2010. El segundo apartado se enfoca en el proceso de paz entre el gobierno de Juan Manuel Santos y las FARC, así como en el Acuerdo Final signado por ambas partes. La tercera sección analiza los antecedentes de la Justicia Transicional en Colombia así como el Sistema Integral de Verdad, Justicia, Reparación y No Repetición derivado de dicho acuerdo. El cuarto y último apartado analiza la propuesta de Lederach para la creación de Infraestructuras para la paz y su importancia para la creación de un entorno favorable para la construcción de paz, considerando a la Justicia Transicional como un elemento central. El trabajo concluye con un análisis de los mecanismos de vinculación entre la Justicia Transicional y las Infraestructuras para la paz en Colombia.

\section{El conflicto armado colombiano}

El territorio colombiano se encuentra fragmentado por tres cordilleras, que genera cinco regiones geográficas naturales y culturales: Andina, Costa Norte, Orinoquía, Amazónica, Costa Pacífica e Insular. La primera de estas regiones además de ser la sede de los poderes de la República, concentra la mayor parte de la población - el 37\% del total de la población del país (Salazar Mejía, 2010, p. 16)además, genera el 45\% del Producto Interno Bruto (PIB) (Salazar Mejía, 2010, p. 34).

En Colombia -al igual que en el resto de América Latina- los costos de las tierras están determinados tanto por las características físicas en cuanto a riqueza de los suelos, recursos hidráulicos, así como las facilidades de comunicación para el traslado de la producción. Por ello, en el país las mejores tierras están en manos de las personas con extensas propiedades, quienes constantemente aumentan los límites de las mismas mediante la compra forzada o el despojo. Por ello, el resto de la población rural colombiana transita de manera constante de una relativa estabilidad económica a la miseria.

A partir de la segunda mitad de la década de los ochentas, se modificó de manera abrupta el uso de tierras así como la distribución poblacional debido al narcotráfico, el paramilitarismo y el auge del uso de los recursos naturales como el petróleo. A partir de la década de los noventas, la minería a tajo abierto trajo consigo el aumento de abusos en Colombia ${ }^{1}$.

El 9 de abril de 1949, tras el asesinato de Jorge Eliécer Gaitán -promotor de reformas socialescomenzó una revuelta popular en Bogotá que se dispersó al resto del país. Dando inicio al llamado periodo de La Violencia (1948-1958). Durante este periodo los enfrentamientos armados entre grupos vinculados a los partidos políticos se caracterizaron por su crueldad, frecuencia e intensidad, así "el asesinato, la amenaza, el éxodo aseguraban en algunas regiones diferentes formas de acumulación de capital" (Medina, 1989, pp. 24-25).

1 En el periodo de 2004 a 2008 el aumento de las hectáreas destinadas a la minería ha sido de un 253\%, ya que se transitó de 1270609 a 4485910 hectáreas (Grisales Gonzáles y Insuasty Rodriguez, 2016, p. 16) 
En este contexto, se crearon movimientos políticos y guerrillas en defensa de sectores campesinos y populares. En particular los grupos armados ubicados en Marquetalia, Departamento del Tolima - ubicado en el centro de Colombia- formaron un cerco a las grandes propiedades de militantes del Partido Conservador. Quienes promovieron que el gobierno de Guillermo León Valencia (1962-1966) autorizara una operación de las Fuerzas Armadas con el objetivo de eliminar a dichos grupos. El 27 de mayo de 1964 comenzaron las maniobras; sin embargo, el grupo no fue desarticulado, dos años más tarde se trasformó en las FARC.

Pese a los combates con las Fuerzas Armadas, las FARC ampliaron su zona de influencia de manera gradual en regiones del sur de Colombia, así como el Magdalena ubicado al Norte del país (Pearce, 1990, pp. 154-155). El crecimiento cuantitativo de las FARC coincidió con la propagación del narcotráfico en Colombia. Para financiar su lucha, la guerrilla comenzó a cobrar "impuestos de guerra" a los narcotraficantes. Por ello, estas organizaciones ilícitas optaron por formar cuerpos armados de paramilitares para combatir a la guerrilla.

Así, los combates con las Fuerzas Armadas y grupos paramilitares disminuyeron gradualmente la capacidad táctica y operativa de las FARC; por ello, el ofrecimiento del gobierno de Belisario Betancur Cuartas (1982-1986) para iniciar un proceso de paz, fue aceptado por la guerrilla con el objetivo de reestructurar sus capacidades. La propuesta de Betancur consistía en una Ley de Amnistía que permitió la libertad de personas presas que formaban parte de las FARC -y de otras guerrillas-, además de un acuerdo bilateral de cese al fuego, así como las facilidades para la reorganización de las guerrillas en fuerzas políticas legales tras un año de cumplimiento del cese al fuego (Villamizar, 1997, pp. 99-100).

El 28 de marzo de 1984, el Gobierno de Colombia y las FARC firmaron el Acuerdo de La Uribe, el cual no incluía un pacto para la entrega de las armas por parte de la guerrilla (Pearce, 1990, pp. 154155). Hecho que provocó críticas y rechazo por parte de partidos políticos, gremios, organizaciones empresariales, y eclesiales.

Al inicio del mandato de Virgilio Barco Vargas (1986-1990) los acuerdos de paz fueron refrendados. Sin embargo, el 16 de junio de 1987, las FARC emboscaron tropas de las Fuerzas Armadas y asesinaron a 27 personas. Por ello, el Gobierno de Barco declaró rota la tregua con la guerrilla y se retomaron los combates armados.

El 1 de septiembre de 1988, el Gobierno de Barco dio a conocer su Iniciativa de paz, compuesta de fases concretas y vinculantes para su realización. Pese a que las FARC manifestaron su intención por participar en un nuevo proceso, no realizaron el cese al fuego unilateral requerido por el gobierno para iniciar la negociación. Al inicio de la presidencia de César Gaviria (1990-1994) se reanudaron los procesos de paz con distintas organizaciones guerrilleras, ello bajo el modelo de paz diseñado por su antecesor. Las FARC decidieron no negociar con el Gobierno (Villamizar, 1997, p. 123).

Sin embargo, en abril de 1991, una comisión de la guerrilla solicitó asilo en la Embajada de Venezuela con la intención de iniciar una negociación de paz con el Gobierno colombiano. Por ello, entre el $1^{\circ}$ de junio de dicho año y hasta el 10 de octubre de 1992 se realizaron distintas rondas de negociación. Sin embargo, durante ese tiempo no pudo establecerse un cese al fuego bilateral, debido a la escalada de acciones militares por ambas partes.

A mediados de la década de los noventas, los enfrentamientos entre las Fuerzas Armadas, grupos paramilitares y las FARC se recrudecieron, lo que provocó que la población civil fuera el punto de confluencia de las acciones violentas. Por ello, al inicio de su mandato, Ernesto Samper Pizano (1994-1998) propuso ampliar la protección a los Derechos Humanos mediante la aplicación del Protocolo adicional a los convenios de Ginebra relativo a la protección de víctimas de los conflictos armados internacionales (Agirre, 1998, pp. 207-208).

Tras ganar las elecciones presidenciales en junio de 1998, Andrés Pastrana (1998-2002) inició un proceso de paz con las FARC. El 21 de febrero del 2002, el tenso proceso de negociación entre el gobierno colombiano y las FARC terminó con un balance poco favorecedor porque no hubo avances que permitiesen vislumbrar el fin del conflicto. 
Después de la ruptura del proceso de paz con el Gobierno de Pastrana, las FARC iniciaron una serie de amenazas contra alcaldes, integrantes de la fiscalía, del sistema judicial y de los concejos sociales. En este entorno, fue electo presidente Álvaro Uribe Vélez (2002-2006 y 2006-2010), quien implementó una política de Seguridad Democrática y combatió a las FARC durante los dos periodos consecutivos de su mandato. Caso contrario fue la negociación con los grupos paramilitares que integraban las Autodefensas Unidas de Colombia (AUC), que se desmovilizaron en el periodo 2002-20032

Cuando Juan Manuel Santos (2010 -2014 y 2014-2018) inició su primer periodo presidencial se comprometió a continuar con la política de Seguridad Democrática de su antecesor; sin embargo, poco tiempo después comenzó un acercamiento con las FARC que daría inicio al proceso de paz.

\section{Proceso de paz del Gobierno de Juan Manuel Santos con las FARC}

Como ya se mencionó, el presidente Santos se había comprometido a continuar el combate contra las FARC. Pero, el 1 de marzo de 2011 comenzó un ciclo de reuniones exploratorias con las FARC para acordar los mecanismos para iniciar un proceso de paz. Ello tras la serie de negociaciones para la liberación de rehenes por parte de la guerrilla.

El 26 de agosto de 2012 se firmó el Acuerdo General para la Terminación del Conflicto y la Construcción de una Paz Estable y Duradera, que contenía una descripción de las condiciones de negociación y la agenda de discusión compuesta por seis puntos: Desarrollo Agrario Integral, Participación Política, Narcotráfico, Víctimas, Fin del conflicto y mecanismos para la implementación, verificación y refrendación de los acuerdos ${ }^{3}$.

Durante los diálogos con las FARC, hubo varias protestas de rechazo, algunas se originaron debido a los límites restrictivos para la participación de la sociedad civil en el proceso. Porque se les confinó a la intervención en mesas de diálogo alternas con personas representantes del Congreso Nacional, del Programa de las Naciones Unidas para el Desarrollo (PNUD) y de la Universidad Nacional de Colombia. Así como al envío de propuestas mediante una página web creada para ello. Las propuestas y síntesis de las mesas de trabajo con la sociedad civil fueron entregadas a la mesa de negociación entre el gobierno colombiano y las FARC. Las partes en el conflicto podrían decidir si integrarían o no, las recomendaciones emitidas.

Otro tipo de protestas, fueron encabezadas por organizaciones de víctimas debido a que consideraban que no debía negociarse el perdón de los crímenes cometidos por integrantes de la guerrilla. Por ello, el 6 de julio de 2014, las FARC y el Gobierno colombiano aprobaron la Declaración de Principios para la discusión del punto cinco de la agenda enfocado en las personas víctimas del conflicto armado ${ }^{4}$. Por lo que, en los siguientes días grupos de representantes de estas agrupaciones llegaron a La Habana ${ }^{5}$ (Medina, 2016, p. 79) para ofrecer sus testimonios y recomendaciones al proceso.

2 La negociación con las AUC se amparó en el Acuerdo de Santa Fe de Ralito y de la Ley de Justicia y Paz o Ley 975 de 2005. El proceso implicó la desmovilización de más de $31 \mathrm{mil}$ combatientes. Véase http://centromemoria.gov.co/procesode-paz-con-las-autodefensas-unidas-de-colombia-auc/ (Consultado 14/05/2018).

3 El texto completo del Acuerdo General para la terminación del Conflicto y la Construcción de una paz estable y duradera se encuentra disponible en la página web del Alto Comisionado para la paz: http://www.altocomisionadoparalapaz.gov.co/procesos-y-conversaciones/acuerdo-general/Documentos\%20compartidos/ Acuerdo_General_para_la_terminacion_del_conflicto.pdf (Consultado 14/05/2018).

4 El texto completo se puede consultar en: http://centromemoria.gov.co/wp-content/uploads/2015/06/DECLARACIÓN-DEPRINCIPIOS-PARA-LA-DISCUSIÓN-DEL-PUNTO-5-DE-LA-AGENDA-VÍCTIMAS.pdf (Consultado 14/05/2018).

5 La Habana, Cuba fue elegida como la sede de negociación debido a que el Gobierno cubano era uno de los dos países acompañantes del proceso de paz. 
El 24 de agosto de 2016 se firmó el Acuerdo Final para la Terminación del Conflicto y la Construcción de Paz Estable y Duradera entre el Gobierno colombiano y las FARC. El Presidente Santos propuso que para ratificar el Acuerdo se realizaría un plebiscito. El cual se desarrolló el 2 de octubre del mismo año. Los resultados fueron inesperados, ya que con un índice de abstención del 63\%, el 50.21\% de los votos fueron por el $\mathrm{No}^{6}$.

La campaña por el $N o$ fue encabezada por el ex presidente Álvaro Uribe, quien argumentaba que el Acuerdo Final no garantizaba penas de prisión para integrantes de las FARC que hubiesen cometido crímenes graves. Además se cuestionaba la creación de un aparato de Justicia Transicional, en lugar de fortalecer al Sistema Judicial Colombiano. Otro de los puntos argumentados era la garantía de espacios en el Senado y en la Cámara de Representantes a integrantes del partido político que se conformaría por las FARC tras su desmovilización. Este acuerdo se consideraba injusto porque no existía restricción para ocupar dichos espacios en caso de la comisión de delitos de lesa humanidad, entre otros puntos ${ }^{7}$. El presidente Santos y el ex presidente Uribe negociaron sus propuestas de modificación al Acuerdo de paz con las FARC, algunas de las cuales fueron incorporadas a la nueva versión firmada el 12 de noviembre de 2016.

\section{Acuerdo final para la terminación del conflicto y la construcción de paz estable y duradera}

El Acuerdo Final se compone de seis puntos. El primero de ellos se refiere a una Reforma Rural Integral que contempla crear un Fondo de Tierras para distribuir de manera gratuita tres millones de hectáreas provenientes de la extinción judicial, el rescate de baldíos y tierras expropiadas (Acuerdo Final para la Terminación del Conflicto y la Construcción de Paz Estable y Duradera, 2016, p. 14), así como otros mecanismos que garantizarían la distribución de las tierras y el acceso a apoyos para la producción agrícola.

El segundo punto del Acuerdo se refiere a la participación democrática, es decir, a los mecanismos para el ejercicio político por parte de las FARC. Para ello, se garantizaría la distribución equitativa de los recursos destinados a partidos políticos, la transparencia de los procesos electorales mediante una revisión integral del régimen electoral, entre otros puntos (Acuerdo Final para la Terminación del Conflicto y la Construcción de Paz Estable y Duradera, 2016, p. 36). Asimismo, se crearían 16 circunscripciones especiales para la paz con el objetivo de garantizar una mejor integración de zonas especialmente afectadas por el conflicto. Las personas integrantes de las FARC no pueden participar en la elección de cargos de representación de dichas zonas; sin embargo, tendrían asegurados cinco curules en el Senado y el mismo número en la Cámara de Representantes (Acuerdo Final para la Terminación del Conflicto y la Construcción de Paz Estable y Duradera, 2016, p. 71).

El tercer punto se refiere al acuerdo de cese al fuego y al procedimiento de dejación de armas. Está compuesto por 25 protocolos de procedimientos para el desarme, la desmovilización y la reintegración de las personas pertenecientes a las FARC, detallando los mecanismos de verificación, monitoreo y logística.

El cuarto punto del acuerdo se enfoca en la solución al problema de las drogas ilícitas mediante un programa de sustitución de cultivos ilícitos vinculados a planes integrales de desarrollo en las áreas afectadas en el marco de la Reforma Rural Integral (Acuerdo Final para la Terminación del Conflicto

6 "Las razones por las que el "No" se impuso en el plebiscito en Colombia", BBC Mundo, http://www.bbc.com/mundo/ noticias-america-latina-37537629 (consultado el 04/10/2016).

7 "Colombia: qué quieren cambiar de los acuerdos de paz con las FARC los promotores del "No" y cuán factible es que lo consigan”, BBC Mundo, http://www.bbc.com/mundo/noticias-america-latina-37582078 (consultado 07/10/2016). 
y la Construcción de Paz Estable y Duradera, 2016, p. 102). Así como la creación de programas para la prevención del consumo de drogas y la comercialización de las mismas.

El quinto punto se refiere a la atención a las personas víctimas del conflicto armado mediante la creación del Sistema Integral de Verdad, Justicia, Reparación y No Repetición, el cual se analizará más adelante.

El sexto y último punto del Acuerdo alude a los mecanismos de implementación y verificación, los cuales serán organizados mediante un Plan Marco para la Implementación de los Acuerdos con una vigencia de diez años. El Plan será monitoreado por la Comisión de Seguimiento, Impulso y Verificación a la Implementación del Acuerdo Final, que elaborará un cronograma detallado de los mecanismos para implementar y verificar los acuerdos (Acuerdo Final para la Terminación del Conflicto y la Construcción de Paz Estable y Duradera, 2016, p. 197). Además, se deberá promover la participación social, de grupos empresariales y de personas representantes de organismos internacionales en dichos procedimientos.

El Acuerdo Final contiene una serie de protocolos anexos que detallan los puntos centrales del proceso de Desmovilización, Desarme y Reintegración de las FARC, las delimitaciones geográficas de las zonas transitorias de normalización, las rutas de desplazamiento de las personas ex combatientes con dirección a dichas zonas, entre otros.

El 24 de noviembre de 2016 se refrendó el Acuerdo Final mediante votación tanto en la Cámara de Representantes como en el Senado, iniciando con ello el proceso de implementación del mismo. Uno de los puntos que destacan del Acuerdo Final firmado entre el Gobierno de Colombia y las FARC fue la creación del Sistema Integral de Verdad, Justicia, Reparación y No repetición, el cual constituye el mecanismo de Justicia Transicional de los acuerdos.

\section{Justicia Transicional en Colombia}

Como ya se hizo mención, en 1997 durante la presidencia de Ernesto Samper se incorporaron elementos del Derecho Internacional Humanitario al marco legal de atención a las personas víctimas del conflicto armado colombiano.

El reconocimiento de las personas víctimas en Colombia ha sido producto de su organización y movilización, tanto para reclamar por las violaciones sufridas como para demandar el reconocimiento social de su inocencia y por ende, el fin de la segregación social. Es decir, “(...) la aparición de las [personas] víctimas como sujetos públicos de memoria y justicia es un proceso que supone el rompimiento del estado de marginalidad al que (...) han sido sometidos (...)” (Cepeda y Girón, 2005, p. 269). Cuestionando con ello, la normalización de la impunidad y los discursos que justifican la existencia de personas víctimas del conflicto armado.

$\mathrm{Si}$ bien, las organizaciones de personas víctimas del conflicto armado participaron en las mesas de negociación desarrolladas durante la Administración de Andrés Pastrana, su presencia como figura social fue reconocida hasta la promulgación de la Ley 975 de 2005 o Ley de Justicia y Paz ${ }^{8}$. En dicha Ley, se reconocen los derechos de las personas víctimas: reconocimiento de la verdad de los hechos, justicia, reparación y derecho a la memoria (Uprimny, 2006, p. 13). Por ello, la Ley 975 es el comienzo de la inclusión de la Justicia Transicional en Colombia.

De acuerdo con Heidi Abuchaibe (2010) la Justicia Transicional se define como:

toda la variedad de procesos y mecanismos asociados con los intentos de una sociedad por resolver los problemas derivados de un pasado de abusos a gran escala, a fin de que (...) [las personas] responsables rindan cuentas de sus actos, servir a la justicia y lograr la reconciliación. Tales mecanismos pueden ser judiciales o extrajudiciales y tener distintos niveles de participación internacional (o carecer por complejo [sic] de ella), así como abarcar el

8 Véase texto completo: https://www.cejil.org/sites/default/files/ley_975_de_2005_0.pdf (Consultado 14/05/2018) 
enjuiciamiento de personas, el resarcimiento, la búsqueda de la verdad, la reforma institucional, la investigación de antecedentes, la remoción del cargo o combinaciones de todos ellos" (Abuchaibe, 2010, p. 304).

La Justicia Transicional implica un proceso de transformación político y judicial. Que se caracteriza por la inclusión de elementos internacionales para la sanción de crímenes de guerra y de lesa humanidad. El objetivo central es la protección de los derechos de las personas víctimas, es decir, el derecho a la verdad, la justicia, la reparación del daño y las garantías de no repetición.

El derecho a la verdad implica un recurso que le permite a la persona víctima y a sus familiares conocer la realidad del abuso sufrido, es decir:

"la identificación de [la autoría material e intelectual del hecho], las causas que originaron el abuso, y, en el caso de las desapariciones forzadas y muertes, conocer las circunstancias en que ellas ocurrieron y el destino y ubicación de las [personas] víctimas o sus cuerpos" (Bernales Rojas, 2016, p. 279).

Para cumplir dicho derecho, en la Justicia Transicional se incluyen mecanismos a nivel judicial así como la creación de Comisiones de Verdad o de Memoria. Éstas reciben información de las personas víctimas para identificar los distintos patrones de violación a los derechos humanos. Además, tienen un carácter oficial, temporal y no judicial.

El derecho a la justicia incluye los procesos de judicialización para esclarecer y atribuir responsabilidad penal a las personas autoras de los crímenes. En el caso del derecho a la reparación del daño, éste implica la responsabilidad del Estado para brindar a las personas víctimas herramientas que les permita construir proyectos de vida que mejoren su situación respecto a las consecuencias de las violaciones vividas.

Las principales medidas de reparación son, las indemnizaciones a personas víctimas y rehabilitarlas en una condición cercana antes del proceso traumático, así comoel derecho a la no-repetición. Éste último derecho se orienta a eliminar las causas estructurales de las violaciones de derechos humanos ${ }^{9}$.

En el caso de Colombia, las bases de la Justicia Transicional se encuentran en la Ley de Justicia y Paz que estableció como requisito de cualquier pacto, que se garanticen los derechos a la verdad, la justicia, reparar los daños y las garantías de no repetición. En los años 2010 y 2012 se expidieron las leyes 1424 y 1592 -respectivamente- que fortalecían a la Ley de Justicia y Paz. La primera de ellas, estableció los mecanismos mediante los cuales se organizó la presentación de integrantes de grupos paramilitares ante instancias de justicia. En tanto que la ley 1592 amplió el concepto de persona víctima lo que permitió regular los procedimientos de reparación del daño (Rúa, 2015, p. 85).

En el año 2011, el Gobierno de Juan Manuel Santos expidió la Ley de Víctimas y de Restitución de Tierras $^{10}$, la cual establece parámetros de justicia distributiva que permiten modificar las relaciones de exclusión social en las que se encontraban las personas víctimas antes del daño (Abuchaibe, 2010, p. 304). Para ello, se crearon unidades administrativas para atender a las personas víctimas, y para la restitución de tierras. Entre ellas se creó la Dirección de Justicia Transicional dependiente del Ministerio de Justicia, cuyas funciones son la coordinación interinstitucional para el desarrollo de políticas y programas de Justicia Transicional.

Además se creó el Centro Nacional de Memoria Histórica (CNMH) cuyo objetivo es preservar la memoria del conflicto, contribuir al conocimiento de la verdad, apoyar el proceso de dignificación de las personas víctimas y construir un legado documental que contribuya a evitar la repetición del daño ${ }^{11}$.

9 Véase "Garantías para la no repetición”, Unidad de Víctimas del Gobierno de Colombia, http://www.unidadvictimas.gov. co/es/garantias-de-no-repetición/173 (Consultado 14/05/2018)

10 El Texto completo puede consultarse en http://www.centrodememoriahistorica.gov.co/ley-de-victimas (Consultado $14 / 05 / 2018)$

11 Véase http://www.centrodememoriahistorica.gov.co 
En el año 2012, fue aprobado el Acto Legislativo 01 mediante el cual se estableció el Marco Jurídico para la Paz ${ }^{12}$, el cual elevó a un plano constitucional la Justicia Transicional en Colombia (Rúa, 2015, p. 96). Así, cuando se firmó el Acuerdo Final entre el Gobierno colombiano y las FARC, pudo establecerse un sistema integral de Justicia Transicional en el país apoyándose en los casi diez años de experiencia colombiana en dicha materia.

\section{Sistema Integral de Verdad, Justicia, Reparación y No Repetición}

A partir de 1985 -año de inicio para aplicar la Ley de Víctimas de 2011- se calcula que el número de personas víctimas en Colombia superaba los seis millones (Aranguren, 2016, p. 1). Por ello, durante el proceso de negociación entre el Gobierno colombiano y las FARC, más de tres mil personas víctimas participaron en cuatro foros de consulta en las ciudades de Villavicencio, Barranquilla, Barrancabermeja y Cali. Y como ya se hizo mención, un grupo en su representación viajó a La Habana para dar a conocer su testimonio y propuestas.

El Acuerdo Final delimitó el Sistema Integral de Verdad, Justicia, Reparación y No Repetición, que se diseñó de manera flexible para que atienda las necesidades de las personas víctimas de acuerdo a las comunidades y territorio en el que se encuentren. Es decir, el sistema se enfoca en el reconocimiento y la satisfacción de los derechos de las personas víctimas. Además de la creación de una subcomisión de género cuya función es hacer recomendaciones para una adecuada aplicación de este enfoque en las medidas de reparación.

El Sistema se compone de tres elementos, el primero de ellos es una unidad para la búsqueda de personas dadas por desaparecidas que coordinará la implementación de acciones humanitarias para la búsqueda e identificación. Esta unidad no sustituye las investigaciones judiciales por lo que tiene un carácter humanitario, independiente y autónomo (Acuerdo Final para la Terminación del Conflicto y la Construcción de Paz Estable y Duradera, 2016, p. 129).

El segundo elemento que compone el Sistema, es la Comisión para el Esclarecimiento de la Verdad, la Convivencia y la No Repetición cuyo objetivo es ofrecer una explicación amplia de la complejidad del conflicto, promover el reconocimiento de las personas víctimas y las responsabilidades de quienes participaron en los actos de violencia así como fomentar las garantías de no repetición. La comisión tiene un carácter transitorio, independiente y extra- judicial (Acuerdo Final para la Terminación del Conflicto y la Construcción de Paz Estable y Duradera, 2016, p. 129).

El tercer y último elemento que compone el sistema es la Jurisdicción Especial para la Paz (JEP) 13 cuyo objetivo será investigar, juzgar y sancionar las graves violaciones a los derechos humanos y las infracciones al Derecho Internacional Humanitario cometidas en el contexto y en razón del conflicto armado. Se compone de una Sala de Reconocimiento y Responsabilidad, una Sala de Amnistía e Indulto, una Sala de definición de Situaciones Jurídicas, una Unidad de Investigación y Acusación, así como un Tribunal para la Paz (Acuerdo Final para la Terminación del Conflicto y la Construcción de Paz Estable y Duradera, 2016, p. 152).

La JEP será manejada mediante la justicia penal colombiana -aunque contará con la asesoría de personas extranjeras especialistas en Justicia Transicional-, y se ocupará exclusivamente -y de manera transitoria por diez años- de las conductas relacionadas de manera directa o indirecta con el conflicto armado. Sin embargo, sólo atenderá las solicitudes presentadas durante los primeros dos

12 El texto completo puede consultarse en http://www.altocomisionadoparalapaz.gov.co/desarrollos-legistlativos-paz/marcojuridico-para-la-paz/Documentos\%20compartidos/Acto-Legislativo-N-01-del-31-de-julio-de-2012-4.pdf

13 El 28 de marzo de 2017 fue aprobado por la Cámara de Representantes el proyecto de la Jurisdicción Especial para la Paz. 
años de su funcionamiento. Además, en caso de acciones de tutela ${ }^{14}$ la Corte Constitucional será la última instancia de decisión.

Los procesos ante la JEP iniciarán cuando se presenten ante la Sala de Reconocimiento de Responsabilidad, los informes proporcionados por la Unidad de Investigación y Acusación ${ }^{15}$, así como los reconocimientos de responsabilidad por integrantes de las FARC. La sala distinguirá entre los delitos no sujetos amnistía como los de lesa Humanidad y los delitos sujetos a amnistía. En el primer tipo de delitos, se remitirán para ser juzgados al Tribunal para la Paz. En el segundo tipo, se enviarán a la sala de amnistías e indultos o bien a la sala de definición de situaciones jurídicas que determinará la situación legal de aquellas personas que no sean objeto de amnistía, pero que tampoco hayan sido enviados al Tribunal para la Paz (Acuerdo Final para la Terminación del Conflicto y la Construcción de Paz Estable y Duradera, 2016, p. 157).

En cuanto a las sanciones, se dividirán en tres tipos las cuales dependerán del momento del reconocimiento de la responsabilidad en las acciones. El primero de ellos serán las sanciones denominadas propias que se dictarán a quienes reconozcan su responsabilidad ante la Sala de Reconocimiento, las penas serán retributivas y restaurativas por lo que se realizarán obras y trabajos de reparación del daño. El segundo tipo, serán las sanciones alternativas que se dictarán a quienes reconozcan tardíamente su responsabilidad, las penas también tendrán un carácter restaurativo, así como sanciones de privación de la libertad hasta por diez años. Por último, cuando no exista un reconocimiento de la responsabilidad se aplicarán sanciones ordinarias con penas de hasta 20 años de privación de la libertad (Acuerdo Final para la Terminación del Conflicto y la Construcción de Paz Estable y Duradera, 2016, pp. 164-165).

En cuanto a la amnistía e indultos únicamente aplicará a los delitos vinculados a la rebelión, excluyendo a los delitos de lesa humanidad, los graves crímenes de guerra, el secuestro, la tortura, la desaparición forzada, la violencia sexual, el desplazamiento forzado y el reclutamiento de menores, entre otros (Acuerdo Final para la Terminación del Conflicto y la Construcción de Paz Estable y Duradera, 2016, p. 295).

De esta manera, cada uno de los elementos que componen al Sistema Integral de Verdad, Justicia, Reparación y No Repetición contribuyen no sólo a garantizar los derechos de las personas víctimas, sino que se constituye en uno de los pilares de las Infraestructuras para la paz en Colombia.

\section{Infraestructuras para la paz}

Tradicionalmente los trabajos para la paz se han vinculado a las etapas del conflicto, es decir, acciones de prevención durante el pre-conflicto, acciones de intervención durante el conflicto, y acciones de mantenimiento, establecimiento y consolidación de paz durante el postconflicto. Este tipo de acciones, se caracterizan por ser implementas por organizaciones exógenas a las sociedades en conflicto como organizaciones internacionales, entre otras. Sin embargo, conllevan el riesgo de que sus objetivos no se concreten debido a que la población en conflicto participe poco.

Por ello, desde distintos círculos académicos y organizaciones sociales se ha transitado hacia la construcción de paz. La cual concibe a la paz como un proceso impulsado tanto por grupos locales, regionales como internacionales. Que realizan acciones para la promoción del desarrollo económico, el

14 Mecanismos de protección de los Derechos Constitucionales.

15 La Unidad de Investigación y Acusación tendrá como función investigar y presentar ante el Tribunal para la Paz a las personas cuyos casos hayan sido remitidos por la Sala de reconocimiento de verdad y responsabilidad. Además, decidirá las medidas de protección a las personas víctimas o que hayan prestado su testimonio; así como solicitará al Tribunal dicte las medidas cautelares convenientes a quienes se encuentren bajo proceso con el objetivo de garantizar el buen desarrollo de éste (Acuerdo Final para la Terminación del Conflicto y la Construcción de Paz Estable y Duradera, 2016, p. 159). 
respeto de los derechos humanos, la equidad de género, la participación democrática, entre otras, sin la necesidad de esperar al término del conflicto, es decir, a la etapa del post conflicto.

Una característica de la construcción de paz es promover que la sociedad civil ${ }^{16}$ participe en generar políticas y proyectos de desarrollo que contribuyan a la prevención de conflictos. Para ello, se fomenta la adquisición de herramientas y la mejora de habilidades para la toma de decisiones, lo cual contribuye al empoderamiento de la sociedad civil.

De acuerdo con John Paul Lederach (1997), el trabajo en red de la sociedad civil y el Gobierno contribuye a la creación de Infraestructuras para la paz. Las cuales son un mecanismo para identificar las dinámicas de interdependencia entre los distintos grupos sociales e instituciones para diseñar e implementar estrategias de respuesta inmediata ante las crisis, así como medir su capacidad -y compromiso- para la construcción de paz.

Lederach señala que las Infraestructuras para la paz se caracterizan por ser "dinámicas, flexibles y adaptables a la vez, y, sin embargo, al mismo tiempo [son] estructuras que tienen forma y se mueven en una dirección impulsada por la visión y el objetivo [ de construcción de paz]”(Lederach, 1997, p. 119). Para ello, las actividades realizadas en el marco de las Infraestructuras se enfocan en tres dimensiones: el cambio social, el impulso a las labores desarrolladas por las localidades, y la reconciliación de las relaciones sociales. De acuerdo con el PNUD a las actividades señaladas por Lederach se pueden agregar el fortalecimiento de la gobernabilidad y la cultura de paz (PNUD, 2009, p. 25).

Las Infraestructuras para la paz operan principalmente:

"en colectividades expuestas a la parte más cruda de la violencia cultural y estructural, aportando no sólo elementos objetivos (salud, educación, vivienda, saneamiento del entorno y del medio ambiente) sino también una atención integral de la persona, sin olvidar las cuestiones de género, grupos etarios e identidad” (Müller, 2015,p.73).

En la actualidad, las Infraestructuras para la paz se han implementado en países como Ghana, Uganda, Kenia, Colombia entre otros. Cuyas experiencias se caracterizan por responder a las necesidades específicas de cada sociedad.

Sin embargo, mantienen algunos rasgos en común. Por ejemplo, su capacidad para establecer un vínculo con los tres niveles de gobierno: local, estatal -o departamental- y nacional, fortaleciendo el impacto de las actividades desarrolladas en los distintos órdenes territoriales para la atención de necesidades básicas inmediatas como el acceso al agua, servicios de salud, entre otros. Lo cual fortalece el trabajo en red entre comunidades, organizaciones sociales y gobiernos.

De acuerdo con van Tongeren (2012), las Infraestructuras para la paz se integran por elementos que realizan un trabajo en red para construir paz y garantizar su sostenibilidad. Éstos pueden variar dependiendo las características y necesidades de las sociedades en conflicto, entre los cuales destacan los Comités o Consejos de Paz encargados de promover el diálogo entre las partes del conflicto así como contribuir a la reconciliación social (van Tongeren, 2012, pp. 98-99); los secretariados o ministerios de paz, y las Comisiones de Verdad, Instancias de verificación de los acuerdos y otros espacios relacionados con la etapa de post-conflicto (Pfeiffer, 2014, p. 7).

Dentro de dichos elementos, destacan los Comités de Paz los cuales son integrados por personas con prestigio comunitario, quienes tienen la capacidad para vincularse a agrupaciones políticas diversas. El principal objetivo de los Comités es la reducción de las violencias mediante el diálogo entre las partes del conflicto, y con ello contribuir a la reconciliación social (van Tongeren, 2012, pp. 98-99).

Los Comités de Paz pueden organizarse desde el gobierno o bien desde las comunidades. En el primer caso, su objetivo es la organización de los distintos elementos gubernamentales que componen

16 En el presente artículo se entenderá como sociedad civil al espacio en el que confluyen organizaciones sociales con contenidos ideológicos heterogéneos con la presencia de nuevas identidades y subjetividades, cuyas acciones confrontan y limitan el poder (Tejeda, 2014, p. 152). 
las Infraestructuras para la Paz (Pfeiffer, 2014, p. 6). En cuanto a los comunitarios, se les denomina como Comités Locales de Paz. Los cuales se caracterizan por funcionar como un elemento para la toma de decisiones y la creación de consenso en las localidades donde se ubican (van Tongeren, 2013, p. 34). Además, los Comités Locales pueden tener un carácter formal al contar con una participación activa del gobierno. Sin embargo, ello no es un requisito forzoso para su funcionamiento.

Las infraestructuras para la paz no tienen una restricción temporal, porque pueden establecerse en cualquier etapa del conflicto. Y su principal objetivo es fomentar la participación de la sociedad civil para transformar las instituciones mediante el estímulo de propuestas de desarrollo humano, el manejo de conflictos, y el pleno ejercicio de los derechos de la ciudadanía basados en la justicia y la dignidad.

El desarrollo de las Infraestructuras para la paz es un proceso sinérgico que puede fomentar los derechos de las víctimas: derecho a la verdad, a la justicia, a la reparación del daño y a la no repetición. En especial porque al participar la sociedad civil como personas agentes por la paz se convierte en un elemento primordial para evitar pactos basados en el perdón y el olvido. Y con ello, se rompe la supuesta discordancia entre la construcción de paz y la justicia transicional, porque ambas tienen como objetivos reconciliar y en la medida de lo posible, el cambio en las relaciones en una sociedad en conflicto.

\section{Conclusiones}

Durante el siglo XX, los acuerdos firmados entre el Gobierno colombiano y distintos grupos armados se caracterizaron por no considerar a las personas víctimas del conflicto armado y por ende, no sancionar los crímenes cometidos por las partes en el conflicto. Porque se consideraba que aplicar la justicia impedía la firma de acuerdos para la desmovilización (Saffon, 2016, p. 89).

De esta manera, el Acuerdo Final para la Terminación del Conflicto y la Construcción de Paz Estable y Duradera firmado entre el Gobierno colombiano y las FARC en el año 2016 resulta innovador tanto por el tipo de medidas para juzgar los crímenes graves, como por el tipo de sanciones que no sólo considerarán penas restrictivas de la libertad sino también de medidas para reparar el daño y de restauración.

Lo cual implicará involucrar a las personas juzgadas en las actividades para el desarrollo territorial enfocadas en el mejoramiento de la economía, la participación política, la adecuada restitución de tierras, el retorno de la población desplazada y la mejora de las relaciones sociales en las comunidades.

Desde el año 2000, en las regiones más vulnerables al conflicto armado colombiano se han creado diversos modelos de Comités Locales de Paz. Por ejemplo, el Consejo Comunitario La Gloria en el Departamento del Valle (sudoeste de Colombia); la Asociación de Trabajadores Campesinos del Carare, ubicada en el Departamento del Santander (nororiente del país), así como los Laboratorios de Paz (con apoyo de la Unión Europea) como el Programa Suizo para la Promoción de la Paz en Colombia SUIPPCOL, entre muchos otros. Estas organizaciones sociales tienen como característica su capacidad para fomentar la participación y el compromiso comunitario en el diseño y desarrollo de medidas para la atención de las necesidades básicas inmediatas.

Los Comités Locales y laboratorios de paz, podrían ser el mecanismo para el cumplimiento de las sanciones para reparar el daño y de restauración, debido a su capacidad para establecer un trabajo en red entre las comunidades y los tres niveles de gobierno. De esta manera, el Sistema Integral de Verdad, Justicia, Reparación y No Repetición fortalecería su presencia territorial, porque además de las actividades que se realizan para la búsqueda de personas dadas por desaparecidas y la investigación de delitos, el cumplimiento de sanciones restaurativas estaría vinculado a las acciones realizadas desde las comunidades.

Las acciones realizadas por el CNMH para integrar el Archivo de Derechos Humanos ${ }^{17}$ son una forma para vincular al Sistema Integral -en especial a la JEP- con las Infraestructuras para la paz. Ya que la integración de dicho archivo ha sido producto de la colaboración con personas víctimas del

17 El archivo se compone de cerca de varios documentos digitalizados provenientes de 130 archivos de organizaciones de personas víctimas y de defensa de los Derechos Humanos. Véase: http://www.centrodememoriahistorica.gov.co/areastrabajo/archivos-de-derechos-humanos/registro-especial-de-archivos-de-derechos-humanos (consultado 17/05/18) 
conflicto armado y organizaciones sociales defensoras de DH para recuperar sus testimonios y digitalizar los documentos y pruebas del delito que sufrieron. Este trabajo ha permitido construir una red de testimoniales que pueden fortalecer las acciones de la JEP ${ }^{18}$.

Así, al vincular al Sistema Integral de Verdad, Justicia, Reparación y No Repetición con las Infraestructuras para la Paz en Colombia, se contribuiría no sólo a garantizar los derechos de las personas víctimas, sino también a impulsar procesos de resiliencia y reconciliación de las relaciones sociales en Colombia.

\section{Índice de Siglas}

$\begin{array}{ll}\text { AUC } & \text { Autodefensas Unidas de Colombia } \\ \text { CNMH } & \text { Centro Nacional de Memoria Histórica } \\ \text { FARC } & \text { Fuerzas Armadas Revolucionarias de Colombia } \\ \text { ELN } & \text { Ejército de Liberación Nacional } \\ \text { EPL } & \text { Ejército Popular de Liberación } \\ \text { JEP } & \text { Jurisdicción Especial para la Paz } \\ \text { PNUD } & \text { Programa de las Naciones Unidas para el Desarrollo }\end{array}$

\section{Referencias}

Abuchaibe, Heidi (2010). La declaración del milenio y la justicia transicional en Colombia. Oasis, Num. 15 Nov., 301-314. Recuperado de http://revistas.uexternado.edu.co/index.php/oasis/article/ view $/ 3174$

Acuerdo Final para la Terminación del Conflicto y la Construcción de Paz Estable y Duradera. (2016). Oficina del Alto Comisionado para la Paz. Recuperado de http://www.mesadeconversaciones. com.co/sites/default/files/24-1480106030.11-1480106030.2016nuevoacuerdofinal-1480106030. pdf.

Agirre, Jon. (1998). Colombia un pueblo sentenciado a muerte. San Sebastián: Tercera Prensa.

Aranguren, Romero, Juan Pablo (2016). Managing Testimony and Administrating Victims: Colombia's Transitional Scenario under the Justice and Peace Act, [Manejo de Testimonios y Administración de Víctimas: Escenario de Transición de Colombia bajo la Ley de Justicia y Paz]. Alemania: Springer.

Bernales Rojas, Gerardo. (2016). El derecho a la verdad. Estudios Constitucionales, Año 14, No. 2, 263-304.

Cepeda, Castro, Iván y Girón, Ortiz, Claudia. (2005). La segregación de las víctimas de la violencia política. En Angelika Rettberg (Ed.), Entre el perdón y el paredón: preguntas y dilemas de la justificia transicional (pp. 259-282). Bogotá: Universidad de los Andes, Ediciones Uniandes, International Development Research Centre.

Grisales Gonzáles, Daniel y Insuasty Rodriguez, Alfonso (2016). Minería, conflictos territoriales y derechos de las víctimas. Medellín: Grupo de Investigación para la transformación social KAVILANDO, Grupo de investigación GIDPAD del Centro Interdisciplinario de Estudios Humanísticos (CIDEH).

Lederach, John Paul. (1997). Building Peace: Sustainable Reconciliation in Divided Societies [Construyendo Paz: Reconciliación Sostenible en Sociedades Divididas]. Washington, D.C.: United States Institute of Peace.

18 El 17 de mayo de 2018 el CNMH puso a disposición de la JEP los 80 informes elaborados por el centro, los cuales contienen testimonios de personas víctimas del conflicto armado. Además ofreció acceso al Archivo de Derechos Humanos. 
Medina, Medófilo. (1989). Bases urbanas de la violencia en Colombia Historia Crítica, Enero-Junio, 1989, 20-32. Recuperado de http://historiacritica.uniandes.edu.co/view.php/11/index.php?id=11

Medina, Medófilo. (2016). El proceso de paz de la Habana en la historia y en la actualidad. En Eduardo Rueda, Sara Victoria Alvarado y Pablo Gentili (Eds.), Paz en Colombia : perspectivas, desafíos, opciones (pp. 73-82). Buenos Aires: Consejo Latinoamericano de Ciencias Sociales,.

Müller, Miriam. (2015). Infraestructuras de paz. Introducción al concepto. En Serena Eréndira Serrano Oswald, Úrsula Oswald Spring y Diana De la Rúa Eugenio (Eds.), América Latina en el camino hacia la paz sustentable: herramientas y aportes. (pp. 69-86). Guatemala: Respuesta para la Paz, Facultad de Ciencias Sociales Guatemala.

Pearce, Jenny. (1990). Colombia dentro del Laberinto. Bogotá: Altamir Ediciones.

Pfeiffer,Silke.(2014).Infraestructuras dePazen Colombia.Recuperado de http://www.berghof-foundation. org/fileadmin/redaktion/Publications/Other_Resources/20141015_Pfeiffer_PI_Colombia_es.pdf

PNUD, Programa Reconciliación y Desarrollo Redes. (2009). Redes de construcción de paz. Bogotá: Programa de las Naciones Unidas para el Desarrollo, Área de Paz, Desarrollo y Reconciliación.

Rúa, Delgado, Carlos Felipe. (2015). Los momentos de la justicia transicional en Colombia. Revista de Derecho, Núm. 43, enero-junio, 71-109.

Saffon, María Paula (2016). Colombia: La sofisticación del acuerdo sobre víctimas en el proceso de paz. En Eduardo Rueda, Sara Victoria Alvarado y Pablo Gentili (Eds.), Paz en Colombia: perspectivas, desafíos, opciones. (pp. 89-90). Buenos Aires: Consejo Latinoamericano de Ciencias Sociales.

Salazar Mejía, Irene. (2010). Geografía económica de la región Andina Oriental (Vol. 121). Cartagena: Banco de la República.

Tejeda, González, José Luis. (2014). Las dimensiones de la Sociedad Civil. Polis: Investigación y Análisis Sociopolítico y Psicosocial, 10, núm. 1, enero-junio, 133-156.

Uprimny, Yepes, Rodrigo. (2006). Introducción. En Rodrigo Uprimny Yepes, María Paula Saffon Sanin, Catalina Botero Marino y Esteban Restrepo Saldarriaga (Eds.), ¿Justifica transicional sin transición? Verdad, justicia y reparación para Colombia (pp. 13-16). Bogotá: Centro de Estudios de Derecho, Justicia y Sociedad, Ediciones Antropos.

van Tongeren, Paul. (2012). Creating Infrastructures for Peace - Experiences at Three Continents [Creando Infraestructuras para la Paz-Experiencias en tres continentes]. Pensamiento Propio, 36-37, 91-127.

van Tongeren, Paul. (2013). Background Paper on Infrastructure for Peace [Antecedentes de las Infraestructuras para la Paz]. Paper presented at the Seminar on Infrastructure for Peace, part of the Sixth Gamip Summit, Global Alliance for Ministries and Infrastructures for Peace, Geneva, Switzerland. http://peaceportal.org/documents/130225323/130281240/Background+Reader+I4P+ seminar/3ac4952d-9220-4dd9-9acb-5c1db8c881e0 Acceso 28/10/16

Villamizar, Darío. (1997). Un Adiós a las Armas. Bogotá: Planeta. 
